\title{
Dynamic Interplay of Cognitive Functioning and Depressive Symptoms in Patients With Parkinson's Disease
}

\author{
Ulrich Schroeders ${ }^{1}$, Johannes Zimmermann ${ }^{1}$, Tamara Wicke ${ }^{2}$, Martina Schaumburg ${ }^{2}$, \\ Elisabeth Lang ${ }^{2}$, Claudia Trenkwalder ${ }^{2,3}$, Brit Mollenhauer ${ }^{2,4}$ \\ on behalf of the DeNoPa Study Group \\ ${ }^{1}$ Department of Psychology, University of Kassel, Germany \\ ${ }^{2}$ Paracelsus-Elena-Klinik, Kassel, Germany \\ ${ }^{3}$ Department of Neurosurgery, University Medical Center Goettingen, Germany \\ ${ }^{4}$ Department of Neurology, University Medical Center Goettingen, Germany
}

\begin{abstract}
Author Note
Ulrich Schroeders (iD https://orcid.org/0000-0002-5225-1122

Johannes Zimmermann (iD https://orcid.org/0000-0001-6975-2356

Tamara Wicke (iD https://orcid.org/0000-0001-9779-4692

Elisabeth Lang (iD https://orcid.org/0000-0001-5748-1376

Claudia Trenkwalder (D) https://orcid.org/0000-0001-6407-1199

Brit Mollenhauer (D) https://orcid.org/0000-0001-8437-3645
\end{abstract}

(C) 2022, American Psychological Association. This paper is not the copy of record and may not exactly replicate the final, authoritative version of the article. Please do not copy or cite without authors' permission. The final article will be available, upon publication, via its DOI: $10.1037 /$ neu0000795 
Study Registration. The DeNoPa study was conducted according to the Declaration of Helsinki and all participants provided informed written consent. Approval was received from the ethical standards committee on human experimentation for all experiments with human participants (approval no. FF89/2008). The study is registered at the German Register for Clinical Trials (DRKS00000540) according to the World Health Organization Trial Registration Data Set.

Open Practices and Data Sharing. Annotated analyses scripts and data to reproduce the main results are provided in an online repository (https://osf.io/ax9nk/).

Disclosure of Conflicts of Interests. Brit Mollenhauer (BM) has received honoraria for consultancy from Roche, Biogen, AbbVie, Servier and Amprion. BM is member of the executive steering committee of the Parkinson Progression Marker Initiative and PI of the Systemic Synuclein Sampling Study of the Michael J. Fox Foundation for Parkinson's Research and has received research funding from the Deutsche Forschungsgemeinschaft (DFG), EU (Horizon2020), Parkinson Fonds Deutschland, Deutsche Parkinson Vereinigung, Parkinson's Foundation and the Michael J. Fox Foundation for Parkinson's Research. The other authors have no conflict of interest to declare.

Acknowledgements of Financial Support. The study was supported by unrestricted research grants from the Paracelsus-Elena-Klinik, Kassel, Germany, Teva Pharma/Lundbeck, GE Healthcare, and the Hermann und Lilly Schilling Foundation, the University Medical Centre Göttingen, the Michael J. Fox Foundation for Parkinson's Research (MJFF). The study sponsors providing support had no influence on the study design, data collection and analysis, the writing of the paper, or the decision to submit the paper. 
Correspondence concerning this article should be addressed to Ulrich Schroeders,

Psychological Assessment, Institute of Psychology, University of Kassel, Holländische Str. 36-

38, 34127 Kassel, Germany, E-mail: schroeders@psychologie.uni-kassel.de 


\begin{abstract}
Objective: We examine the trajectories of and the dynamic interplay between cognitive functioning and depressive symptoms in patients with Parkinson's disease (PD) in comparison to healthy controls $(\mathrm{HC})$ from an intraindividual perspective.

Method: The DeNoPa study is a single-center, observational, longitudinal study with biennial follow-ups over 8 years. The present analyses are based on 123 PD (79 male) and 107 HC (64 male) with a mean age of 64.1 years $(S D=8.3)$. PD and HC completed a battery of neuropsychological tests and scales assessing depressive symptoms. We used a random-intercept cross-lagged panel model to study their trajectories and the dynamic interplay.

Results: Cognitive abilities of PD were on average $d=-0.67$ worse at baseline and $d=-1.22$ at 8-years follow-up in comparison to HC. Depressive symptoms in PD showed a large variability and followed a U-shaped trajectory. From an intraindividual perspective, greater impairments in cognitive abilities were subsequently associated with increased depressive symptoms $(b=-0.60$, $p=.03)$, whereas the effect in the opposite direction was not significant.

Conclusions: We found indication that a decline on a global composite scale of cognition can be seen as precursor of depressive symptoms in patients with PD. To counter cognitive losses and the subsequent mood deterioration, patient education and early cognitive (and behavioral) enrichment seem promising candidates for treatment.
\end{abstract}

Keywords: Parkinson's Disease, Longitudinal Study, Cognitive Functioning, Depressive Symptoms, random-intercept cross-lagged panel 


\section{Key Points}

Question: What is the dynamic interplay between cognitive functioning and depressive symptoms in patients with Parkinson's disease?

Findings: From an intraindividual perspective, a decrease in cognitive functioning was subsequently associated with increased depressive symptoms, but not vice versa.

Importance: To counter cognitive losses and the subsequent mood deterioration, patient education and early cognitive (and behavioral) enrichment seem promising candidates for treatment.

Next Steps: Intensive longitudinal data collection using smartphones may allow for a more finegrained assessment and modeling of the dynamic interplay of non-motor symptoms in patients with Parkinson's disease. 


\section{Dynamic Interplay of Cognitive Functioning and Depressive Symptoms in Patients With Parkinson's Disease}

Parkinson's disease (PD) is the second most common neurodegenerative disease with an increasing prevalence with age, that is, approx. $1 \%$ of the population over 70 years and $2 \%$ over 80 years have PD (Pringsheim et al., 2014). The prevalence of PD is expected to increase due to improvement in medical treatment and increasing life expectancy, with estimates of up to $4 \%$ of the population by the year 2050 (Rocca, 2018). PD is most commonly known as a movement disorder and accordingly the focus in the diagnosis of PD is on motor symptoms (e.g., tremor, rigidity, bradykinesia). However, non-motor symptoms including cognition, depression, and anxiety are also common and severely affect patients' quality of life (Jones et al., 2015). Recently, there have been significant advances in biomarker research (Ferreira et al., 2020) and the underlying neurophysiological pathways of PD are now better understood (e.g., the systemic spreading of alpha-synuclein aggregates; Wang et al., 2019). From the perspective of clinical practice, research on the course of non-motor symptoms and their dynamic interplay is important to possibly establish different pheno- or progression types of the disease, to identify windows for intervention, and to balance the different therapeutic strategies.

\section{Cognitive Functioning in Patients With Parkinson's Disease}

More than $40 \%$ of patients with PD suffer from mild cognitive impairment (MCI) within five years of diagnosis with a high risk of dementia in later stages of the disease (Broeders et al., 2013; Monastero et al., 2018; Pedersen et al., 2017). PD-MCI is defined by a gradual decline in cognitive abilities without significant restrictions in everyday life (for details see the diagnostic criteria in the Guidelines of the Movement Disorder Society Task Force, Litvan et al., 2012). The annual conversion rates to dementia of patients with PD with $\mathrm{MCI}$ are approx. $12 \%$, which is 
higher than the annual progression rates from MCI to dementia of $6-10 \%$ in the general population (Pedersen et al., 2017; Petersen et al., 2009).

Although the majority of studies examined cognitive impairment of patients with PD cross-sectionally, there are more than twenty longitudinal studies that allow studying the course of cognitive decline (for an overview see Muslimović et al., 2007; Roheger et al., 2018). Some studies report a more pronounced impairment in specific cognitive abilities such as memory (Aarsland et al., 2010; Pfeiffer et al., 2014; Yarnall et al., 2014) or visuo-spatial or language ability (Aarsland et al., 2017; "dual syndrome hypothesis”, see also Kehagia et al., 2013). “[...] However, often the impairment is not restricted to a specific cognitive domain, but covers several domains (Muslimović et al., 2005; Hoogland et al., 2018). The evidence for subtypes with specific cognitive impairments (e.g., memory or language) is inconsistent, which is partly due to methodological issues including the heterogeneity of the measurement instruments, the small sample sizes combined with selection effects, and different time points at which the patients with PD are examined in the course of the disease. Muslimović et al. (2007) combined the evidence of 25 longitudinal studies with 901 initially non-demented patients with PD in a comprehensive meta-analysis and examined the cognitive decline with progressing disease across eight cognitive domains using a random-effects model. They found impairments across all cognitive domains 2.5 years after baseline, with the most significant decline in global cognitive ability $(d=.40)$. The view that PD affects many different cognitive abilities corroborates the contemporary view that PD is a multisystem, multipeptide neurodegeneration (Aarsland et al., 2017).

\section{Depressive Symptoms in Patients With Parkinson's Disease}

Clinically significant depressive symptoms occur in approximately $40 \%$ of all patients with PD, although prevalence rates vary strongly depending on the diagnostic criteria and the 
study population (Barone, 2011; Lemke, 2008). In a meta-analysis, Reijnders et al. (2008) summarized the evidence of 36 studies, taking into account the different settings and diagnostic approaches, concluding that $17 \%$ of PD patients meet the criteria for major depressive disorder, $22 \%$ for minor, and another $13 \%$ for dysthymia. Moreover, the prevalence also depends on the phase of the disease: Several studies showed that the severity of depressive symptoms increases with disease progression (e.g., Ketharanathan et al., 2014; Pankratz et al., 2008; Riedel, Klotsche, et al., 2010), whereby the exact prevalence estimates differ considerably depending on the inclusion criteria, the populations, the measures, and the cutoff values (e.g., von Glischinski et al., 2021; Goodarzi et al., 2016). In the following, we focus on depressive symptoms, that is, a continuous understanding of the underlying disease. Depressive symptoms significantly reduce the quality of life independent of the motor symptoms (Jones et al., 2015; Gallagher et al, 2010; Schrag et al., 2000), and might aggravate disability (Pontone et al., 2015, Ravina et al., 2007; Riedel, Heuser, et al., 2010; Riedel, Klotsche et al., 2010).

Motor symptoms in patients with PD are the most prominent symptoms that severely affect everyday life, which is why dopamine substitution using levodopa or dopamine agonists are established first-line treatments of motor symptoms for the majority of patients. However, any pharmacological treatment has to be evaluated in terms of its effect on motor symptoms and potentially detrimental effects on depressivity and cognitive functioning (Lemke, 2008). Studies dealing with the consequences of such a substitution on mood regulation are inconclusive (Leentjens, 2011; Ryan et al., 2019): In most studies, dopaminergic agonists have been shown to reduce the depressive symptoms (Liao et al., 2020; Schaeffer \& Berg, 2017), but others have reported no effects (Choi et al., 2000), or even a worsening of the symptoms (Jaunarajs et al., 2011; Zhang et al., 2014). Ryan et al. (2019) pointed out that there are complex, structural 
changes in several neurotransmitter systems in patients with PD including dopamine and serotonin, which may contribute to depressive symptoms.

\section{Interplay Between Cognitive Functioning and Depressive Symptoms}

Previous studies outlined an association between depressivity and cognitive performance in patients with PD (Aarsland et al., 2010; Pirogovsky-Turk et al., 2017). For example, Dotson et al. (2010) showed in a longitudinal study on aging that with each episode of elevated depressive symptoms the risk for all-cause dementia increases by $14 \%$. In the case of PD, patients with dementia who had an early onset of symptoms also showed more depressive symptoms (Sanyal et al., 2014). Such findings have often been interpreted as an indication that depression may be a risk factor or a precursor symptom of dementia (Ishihara \& Brayne, 2006). But the direction of effects is unclear: As with all cross-sectional, observational data or longitudinal data where the beginning of change cannot be pinpointed, three different perspectives can be taken: (1) A decline in cognitive functioning can cause the onset or amplification of depressive symptoms; (2) depressive symptoms can precede a cognitive decline or dementia; and (3) both depressive symptoms and cognitive impairment can be results of some third variable or a common underlying mechanism ("common cause model"). In fact, there is evidence for all three perspectives. Petkus et al. (2019) examined the question of directionality with longitudinal data from 362 non-demented participants from the Parkinson's Progression Markers Initiative (PPMI) with bivariate dual change score models. The authors found that over a four-year period, poorer cognitive performance across all cognitive domains predicted increased symptoms of (anxiety and) depression a year later, while the reverse direction was not significant. Accordingly, poor cognitive performance was considered a risk factor for depression. Using the same PPMI dataset (with different exclusion criteria and subsetting different cognitive tasks) Jones et al. (2019) also 
studied the longitudinal relationship over four years with multilevel models. Surprisingly, they found results that completely contradict those of Petkus et al. (2019): More severe depressive symptoms were also related to worse performance on a variety of cognitive abilities. However, additional cross-lagged models demonstrated that changes in depressive symptoms preceded declines in working memory, verbal learning, memory, and global cognition, leading to the conclusion that "depressive symptoms may be a harbinger for future cognitive decline among individuals with PD” (Jones et al., 2019, p. 1111, see also Hanganu et al., 2017). And finally, neuroimaging studies also support the notion that degeneration in the various neurotransmitter systems is relevant not only for the typical motor symptoms but also for non-motor symptoms including depression (Wen et al., 2016) and cognitive dysfunction (Perez-Lloret \& Barrantes, 2016).

\section{The Present Study}

In this study, we aim to better understand the disease-related development of cognitive impairment in patients with PD and to relate the decline to depressive symptoms at an individual level. Among others, the link between cognitive decline and depressive symptoms is important for monitoring of and commitment to the therapeutic intervention. Whereas dementia usually occurs relatively late in the course of the disease, MCI can be detected early on in untreated patients, even at the premotor stage (Goldman \& Postum, 2014). The present work attempts to address the weaknesses of previous research in several respects: First, instead of relying on short, clinical examinations, we administered a detailed neuropsychological assessment. Second, we examine the dynamic interplay between cognitive functioning and depressive symptoms in a large sample of patients with PD in comparison to a healthy control group of elderly people matched with regard to age, sex, and educational background over the course of 8 years with 
biennial follow-ups. Such a longitudinal patient-control group design allows distinguishing between age-related and disease-specific cognitive and emotional changes, respectively. Third, we use the more refined random-intercept cross-lagged panel model (RI-CLPM, Hamaker et al., 2015; Mund \& Nestler, 2019) to study the intraindividual interplay between cognitive functioning and depressive symptoms longitudinally. The traditional and more prevalent CLPM has been criticized because it confounds between- and within-person effects, thus, implicitly assuming that every person varies over time around the same average trend and that there are no trait-like individual differences that endure. However, such an assumption of a homogeneous developmental pattern across individuals (e.g., Jones et al., 2019; Petkus et al., 2019) is neither warranted for cognition in patients with PD (Biundo et al., 2016), nor their depressive symptoms (Dogan et al., 2019). In contrast, the RI-CLPM decomposes the variance of the observed scores into between-person variances (i.e., the stable, time-invariant part) and within-person variance, which enables a more nuanced investigation of the dynamics of processes that take place within individuals (Hamaker, 2012).

The following research questions are answered, each with reference to possible differences between patients with PD and a matched control group:

1. What are the average trajectories of cognitive functioning and depressive symptoms? (mean trajectories)

2. What is the correlation between the stable part of both constructs? (between-person associations)

3. What are the correlations between the time-point specific parts of both constructs? (time-point specific within-person associations) 
4. Is cognitive functioning associated with future depressive symptoms within persons or vice versa? (within-person cross-lagged effects)

5. How inert are the individual trajectories of cognitive abilities and depressive symptoms? (within-person autoregressive effects)

\section{Method}

\section{Sample and Study Design}

The data derives from the ongoing de novo Parkinson project (DeNoPa; Mollenhauer et al., 2013, 2016), a prospective and longitudinal study with patients with de novo PD and neurologically healthy controls (HC) matched with regard to age, sex, and educational background. The overall aim of this single-center, observational study with biennial follow-ups is to adequately describe the course of the development of the disease, improve early diagnosis, and identify potential progression markers. The present analyses are based on the longitudinal study of five measurement occasions at two-year intervals between 2009 and 2021. Participants had to be between 40 and 85 years old, newly diagnosed with PD featuring at least two of the criteria of resting tremor, bradykinesia, and rigidity according to UK Brain Bank Criteria, and had to fulfill de novo PD criteria. Participants with known severe vascular encephalopathy, normal-pressure hydrocephalus or signs or symptoms according to multiple system atrophy or progressive supranuclear palsy (according to consensus criteria, Gilman et al., 1998; Litvan et al., 1996) were excluded. Healthy controls had to be in the same age range, without any active known/treated condition of the central nervous system, and without a family history of idiopathic PD. Antipsychotic drugs were an exclusion criterion both for controls and patients. Controls were matched using frequency matching by age, sex, and education (see also Appendix e-1 in Mollenhauer et al., 2013). 
A total of $123 \mathrm{PD}$ (79 male, 44 female) and $107 \mathrm{HC}$ (64 male, 43 female) with a mean age of $64.1(S D=8.3)$ at baseline were included. All except one participant were German. The distribution of the highest educational attainment was very similar across the groups and quite common for the age distribution in the sample in Germany (see Table 1). At baseline, 19 of the 123 patients with PD (15.4\%) and 6 of 107 controls (5.6\%) received a concomitant medication with antidepressants. At the last measurement occasion, 22 of 93 patients with PD (23.7\%) and 4 of 84 controls (4.7\%) were treated with antidepressants. At the last measurement occasion, 9 patients with PD received anticholinergic medication with Rivastigmine, which is prescribed for patients with Parkinson-related dementia. None of the study participants received antidopaminergic medication at baseline (i.e., de novo patients). Following the German guidelines for the treatment of Parkinson's disease (DGN, 2021), 83 of 123 patients with PD received a PD medication with a levodopa equivalent dosage (determined according to Tomlinson, 2010) of $M=122.9 \mathrm{mg}(S D=62.3 \mathrm{mg})$ at the 2-years follow-up. At the 8-years follow-up, 62 of 93 patients with PD received a levodopa equivalent dosage of $M=151.8 \mathrm{mg}$ $(S D=69.5 \mathrm{mg})$.

The study was conducted according to the Declaration of Helsinki and all participants provided informed written consent. Approval was received from the ethical standards committee on human experimentation for all experiments with human participants (approval no. FF89/2008). The study is registered as an observational and non-interventional study at the German Register for Clinical Trials (DRKS00000540) according to the World Health Organization Trial Registration Data Set. That means, participants may receive advice on medication after each study visit to be shared with their treating neurologist. Participants are not assigned to specific interventions by the investigator (as in a clinical trial). 


\section{Measures}

Both patients and controls completed a battery of neuropsychological tests. We used scores of seven psychometric tests (with a total of 14 scores, see Table 2) that were administered at all time points: Montreal Cognitive Assessment (MoCA; Nasreddine et al., 2005), the Regensburger Word Fluency Test (RWT; Aschenbrenner et al., 2001), the Stroop Test (Bäumler, 1985), the Trail-Making-Test (Tombaugh, 2004), the Verbal Learning and Memory Test (VLMT; Helmstaedter et al., 2001), the subtest Similarities for the Wechsler Adult Intelligence Scale (WIE; von Aster et al., 2006), and the subtest Digit Span of the Wechsler Memory Scale Revised (WMS-R, Härting et al., 2000). We only excluded clinical screenings that had almost no variation in the $\mathrm{HC}$ group (i.e., Clock Drawing test, Mini-Mental State Examination, Visual Object and Space Perception Battery). The assessment covers a broad range of cognitive abilities including memory, language abilities, and executive functioning. Response times of speeded measures (TMT and Stroop) were reverse log-transformed. For outlier removal, we winsorized all raw scores (i.e., $M \pm 2.5 S D$ ). To allow comparisons across measurement time points, we standardized the winsorized raw scores to the baseline measurement in the HC group. Finally, we aggregated all (winsorized and standardized) scores by measure and then equally weighted them into a single score. We used a global score instead of domain-level analyses, because clinical studies often report the simultaneous impairment of several cognitive abilities in patients with PD (Muslimović et al., 2005, 2007), whereas the evidence for domain-specific losses is inconsistent and depends on many (intertwined and partially unknown) factors. In addition, the composite score of overall cognitive ability is more reliable than the individual indicators that often capture a blend of several cognitive abilities (e.g., processing speed and broad visual perception). Finally, the assumption of a uni-dimensional model for all used cognitive ability 
tests is also empirically supported, both in terms of an exploratory factor and a confirmatory factor analysis (for additional information please see OSF repository).

To assess the severity of depressive symptoms in both groups, the scores of two selfreport measures (Beck's Depression Inventory, BDI, Hautzinger et al., 1995, and the Geriatric Depression Scale, GDS, Gauggel \& Birkner, 1999) and a clinical rating (Montgomery-Asberg Depression Rating Scale, MADRS, Schmidtke et al., 1988) were combined. We opt for a composite score of depressive symptoms instead of subcomponents of depression because the diagnostic gain is often limited, which is expressed in very high factor correlations of multidimensional solutions. Such a global composite score of depressive symptoms is also in line with a common metric underlying different measurement instruments (Wahl et al., 2014) and a higher-order subfactor of distress within the internalizing spectrum of the Hierarchical Taxonomy Of Psychopathology, HiTOP, Kotov et al., 2021). Moreover, the assumption of unidimensional measurement models for all scales is empirically supported with confirmatory factor analyses at the item level (for additional information please see OSF repository). A single composite score was used justified by the high zero-order correlations between the scales (e.g., correlations at baseline ranged between .68 and .80 in the overall sample, see also OSF repository). The scales had satisfying reliability estimates (e.g., for the first measurement time point: $\left.\alpha_{\mathrm{BDI}}=.89, \alpha_{\mathrm{GDS}}=.84, \alpha_{\mathrm{MADRS}}=.84\right)$. To allow comparisons across measurement time points, we used the same procedure as for the cognitive ability measures described above. 


\section{Statistical Analysis}

We analyzed the relationship between cognitive functioning and depressive symptoms with a random-intercept cross-lagged panel model (RI-CLPM, Hamaker et al., 2015; Mulder \& Hamaker, 2020; Mund \& Nestler, 2019). The RI-CLPM decomposes the variance of the observed scores into between-person (i.e., the stable, time-invariant part) and within-person variance (i.e., fluctuations over time, for a graphical representation of the model see Figure S1 in the OSF repository). We used an extension of the RI-CLPM to the multi-group case to model both groups (HC vs. PD) simultaneously (see also Mulder \& Hamaker, 2020). To answer the research questions we modeled a) the mean trajectories across groups and constructs. The RICLPM describes three associations between the constructs specifying the subsequent research questions: b) the correlations between random intercepts (between-person associations), c) correlations between the measurement point-specific residuals (time-point specific within-person associations), and d) regressions across constructs on subsequent time points (within-person cross-lagged effects). One advantage in contrast to the traditional cross-lagged panel model (CLPM) is that the autoregressive parameters in the RI-CLPM are not confounded with the timeinvariant part of a construct (for a detailed discussion see Hamaker et al., 2015). Thus, we estimate e) the within-person autoregressive effects.

We used the maximum likelihood estimator with robust estimation of standard errors (MLR) and corrected test statistics. The robust versions (see also Brosseau-Liard et al., 2012; Brosseau-Liard \& Savalei, 2014) of the following fit indices were considered indicators of good model fit: Comparative Fit Index $(\mathrm{CFI})>.95$, Root Mean Square Error of Approximation $($ RMSEA) $<.06$, and Standardized Root Mean Squared Residual $($ SRMR $)<.08$ (Hu \& Bentler, 1999). We used Full Information Maximum Likelihood (FIML) procedure (Schafer \& Graham, 
2002) to handle missing data, which results in unbiased estimates under the assumption of Missing At Random (MAR; Enders, 2010), that is, random missingness after controlling for the effects of additional observed variables. MAR is an assumption that cannot be tested directly (in contrast to Missing Completely At Random). As a sensitivity check, we compared the age, sex, education, cognitive abilities, and depressive symptoms at baseline between the groups of remainers vs. dropouts (i.e., not present at last follow-up). There were systematic differences between both groups for age, education, and cognitive abilities. We, thus, decided to include demographic variables that were present for all participants (i.e., age, education, and sex) as auxiliary variables besides the variables in the analytical model to improve the model-based handling of missing data with FIML (Graham, 2003).

\section{Transparency and Openness}

We report how the measures included in the analyses were selected and all data transformations applied. To foster transparency, the annotated analyses scripts and data to reproduce the main results are provided in an online repository (https://osf.io/ax9nk). All

analyses were conducted with R 4.1.0 (R Core Team, 2021), mainly with the R package lavaan 0.6-9 (Rosseel, 2012).

\section{Results}

\section{Descriptive results}

Table 3 gives the sample sizes, means, and standard deviations of all cognitive ability tasks and depressive symptoms scales for each measurement time point, split by patients vs. controls. For all the univariate and bivariate distributions as well as correlation matrices of all measures at each time point see Figure S2 - S5 in the OSF repository. In the following, we describe the results of the random-intercept cross-lagged panel model, which provided good fit to 
the data: $\chi^{2}=104.8, d f=66, p<.01, \mathrm{CFI}=.979, \mathrm{RMSEA}=.076$ [CI $\left.{ }_{90 \%}: .047, .102\right]$,

$\mathrm{SRMR}=.065$. More precisely, we report changes in the mean structure across time and group, between-person associations, and the within-person effects.

\section{Results of the Random-Intercept Cross-Lagged Panel Model}

Mean trajectories. In line with the literature (Reijnders et al., 2008), patients with PD reported significantly more depressive symptoms than the persons in the age-matched control group at baseline $(d=1.51$; all reported $d$-values are standardized at the standard deviation of the control group at baseline). Although the severity of depressive symptoms decreased at the subsequent follow-ups (indices in the following refer to months after baseline: $d_{\mathrm{FU} 24}=1.03$ and $\left.d_{\mathrm{FU} 48}=0.83\right)$, it began to raise afterwards, $\left(d_{\mathrm{FU} 72}=1.05\right.$ and $\left.d_{\mathrm{FU} 96}=1.38\right)$ indicating a U-shape (see black lines in Figure 1). In the HC group, the average was close to zero at all time points with no time trend. To facilitate the interpretation of the continuous, standardized depressivity score, we also used the Geriatric Depression Scale (GDS-15) as a proxy to assess the severity of depression from a categorial, clinical perspective. Weintraub et al. (2006) studied the diagnostic accuracy of the GDS-15 in a sample of 148 outpatients with idiopathic PD and found a cutoff of 5 or higher as a good indication of a major or minor depression (sensitivity $=.88$;

specificity $=.85$, see also Goodarzi et al., 2016). According to this approximation, $36.1 \%$ of the patients with PD could be flagged as potentially having a depressive disorder. The prevalence rates decrease in the following honeymoon period (27.9\% at 2-years follow-up and $21.1 \%$ at 4 years follow-up), only to slightly rise afterwards (about $25 \%$ at 8 and 10 -years follow-up). Thus, it appears that the level of depression remains similar across the patient group. However, when interpreting the values one has to take into account the dropout rates (see Table 3) and the fact 
that the patients in this observational study received concomitant medication and often psychotherapeutic intervention.

Regarding the cognitive abilities, there was a considerable and almost constant decline for the patients with PD $\left(d_{\text {base }}=-0.67, d_{\mathrm{FU} 24}=-0.75, d_{\mathrm{FU} 48}=-0.88, d_{\mathrm{FU} 72}=-0.94, d_{\mathrm{FU} 96}=-1.21\right)$. For a few cases in the PD group the losses in cognitive performance were substantial (i.e., more than 1.5 SD decline compared to baseline, Yarnall et al., 2014), and the figures steadily increased with progression of the disease. Model-implied values evidenced that $17 \%$ of the PD group crossed the -1.5 SD threshold at the 8-years follow-up (see Figure 1). In contrast, there were almost no cases in the control group indicating that this change was not due to aging processes.

Between-person associations. The between-person variance (expressed in the variance of the random-intercept factors) was two times larger for the patients with PD compared to HC for the depressive symptoms and comparable in size for cognitive functioning. We observed a small non-significant negative relation between intelligence and depressive symptoms in the HC group $(b=-0.08, p=.06)$. For the patients with PD, this association was significant $(b=-0.24, p=.03)$, indicating that at an interindividual level lower cognitive abilities were accompanied by a higher extent of depressive symptoms, and vice versa.

Time-point specific within-person associations. The within-person variances (expressed in the time-point specific residual variances) were more than two times larger in patients with PD for cognitive abilities compared to the HC group, and about three times larger for the depressive symptoms. Negative, close-to-zero associations between cognition and depressivity were found at almost all follow-ups across groups (see Table 4).

Within person cross-lagged effects. The cross-lagged effects mark within-person effects between cognition and depressivity at consecutive points in time. Sometimes these effects are 
also referred to as spill-over effects, because they denote how the state in one domain influences the state in another. The cross-lagged effects showed that a patient's score below their usual level of cognitive abilities at a given time point after baseline was associated with higher levels of depression two years later. From an intraindividual perspective, greater impairments in cognitive abilities at a given time point (i.e., lower scores in comparison to the individual mean) were associated with increased depressive symptoms (i.e., higher scores in comparison to the individual mean) at a subsequent time point in patients with $\operatorname{PD}(b=-0.60, p=.03)$. However, the opposite paths from depressivity to cognition were not significant $(b=-0.03, p=.66)$. To check whether the cross-lagged effects from cognition on depressive symptoms were different from the effects in the opposite direction, we compared the model to a model in which all crosslagged effects in the PD group were constrained to equality. The difference in the cross-lagged effects was statistically significant $\left(\Delta \chi^{2}(1, N=230)=5.8, p=.02\right)$. In comparison, in the HC group, none of the cross-lagged effects were significant.

Within person autoregressive effects. In the RI-CLPM the autoregressive effects do not capture rank-order stability of a trait, but they account for the additional moment-to-moment stability (i.e., inertia or carry-over) of persons' fluctuations over time (Mulder \& Hamaker, 2020). The effects were significant for cognitive abilities in the PD group, demonstrating that patients with greater cognitive impairment relative to their own expected score were likely to experience the same problems relative to their own expected score at the next follow-up. Also, the within-person autoregressive effects of both cognitive abilities and depressive symptoms in the $\mathrm{HC}$ group were significant, which is also reflected in the low intraindividual variation (see Figure 1). 


\section{Discussion}

In the present study, we compared the intraindividual developmental trajectories and the dynamic interplay of cognitive functioning and depressive symptoms of patients with PD with those of a control group that was matched according to age, sex, and educational background. Compared to other longitudinal Parkinson studies, the long study period of eight years after baseline and the implementation of a control group, that enables distinguishing between diseaserelated and aging-related processes, are particular strengths of this study. Using a RI-CLPM allows distinguishing within- from between-person effects, thus, to dismiss the untenable assumption that every person varies over time around the same average trend in favor of a more flexible modeling of intraindividual processes. In the following, we highlight and discuss the main findings.

First, cognitive abilities in the PD group decreased with disease progression, whereas the control group did not show any sign of decline on a global composite score assessed with a broad neuropsychological assessment. With almost a single standard deviation on average at the last follow-up (in comparison to the baseline measurement in the HC group), the losses were significant, which is in line with the literature (e.g., Yarnall et al., 2014). The trajectories of the depressive symptoms followed a U-shaped trend with an improvement 2-4 years after baseline. Thus, the average trajectory of the patients with PD is similar to the typical trajectory of motor symptoms under Levodopa medication. This period in-between has also been labeled "honeymoon" phase (Erro et al., 2016), because at this stage the motor and non-motor impairments are not yet severe, do not fluctuate, and dopaminergic therapy is still relatively continuously effective (Rascol et al., 2003). 
Second, the variability in both constructs in the PD group was very large in comparison to the rather flat trajectories in the HC group: The variances were two times larger for cognitive abilities and three to four times larger for the depressive symptoms. Results of the RI-CLPM also showed that the stable, between-person differences constitute a substantial part of the observed differences. In more detail, in the PD group, between $72-79 \%$ of the total variance in cognition and $59-68 \%$ of the total variance in depressive symptoms at follow-ups could be attributed to a trait-like, time-invariant characteristic of the patient, while the remaining part reflected timevariant influences. Recently, Jones et al. (2020) pointed out that increased intraindividual variability might be predictive of incident cognitive decline among individuals with de novo PD. Thus, a separation between both sources of variances is informative. In addition to the setup of a traditional cross-lagged panel model, it is therefore necessary to introduce a random intercept factor to ensure unbiased cross-lagged estimates (Hamaker et al. 2015). The random intercept factors were significantly negatively correlated in the PD group only, indicating that at an interindividual level lower cognitive abilities were accompanied by more depressive symptoms, and vice versa. At an intraindividual level, we also observed essentially the same pattern of association for the time-specific residual associations between both constructs. In this respect, the results of the present examination show for the first time that the same associations can be detected at an intra- and an interindividual level, which was not necessarily to be expected, as has been repeatedly shown in the psychometric literature (e.g., Mund \& Nestler, 2019).

Third, the main finding of this study is that cognitive losses precede an increase in depressive symptoms in the clinical group only. The effect in the opposite direction was not significant, that is, an increase in depressive symptoms is not followed by a deterioration in cognitive performance (for a similar finding see Petkus et al., 2019). The current results are not 
in line with the notion that depressivity may be used as a precursor symptom of cognitive decline (Jones et al., 2019) or dementia (Ishihara \& Brayne, 2006). On the contrary, the cognitive losses experienced by patients are subsequently accompanied by a marked deterioration in mood. With respect to the question of what might be the underlying mechanisms for (subsequent) depressive symptoms we have to consider several factors such as changes in brain structure and plasticity, inflammatory and neurotrophic factors as well as a decrease in resilience with age (Aarsland et al., 2012). Weintraub et al. (2019, p. 999) described the cumulative prevalence of neuropsychiatric symptoms in patients with PD as ,the result of a perfect storm, with contributing factors including demographic characteristics, diffuse and multiple neurodegenerative disease pathologies, other neurobiological factors, and PD treatments themselves". The results of the present study give an indication that there may nevertheless be a temporal order in the occurrence of non-motor symptoms. To counter the cognitive losses and the following depressive symptoms, early cognitive (and behavioral) enrichment might help to mitigate these processes (Hindle et al., 2014). In addition, patient education including stress management and health promotion seems important (Chlond et al, 2016).

The DeNoPa study makes a sensible complement to other studies of patients with PD such as PPMI: As a single-center study, DeNoPa offers a comparable and consistent neuropsychological assessment, includes a carefully selected control group as a point of comparison, enabling to detect disease-specific changes, and covers a comparatively long period of eight years to date with a comparatively low rate of attrition (not caused by death). Nonetheless, there are some limitations that need to be considered when interpreting the results: First, DeNoPa is an observational study with patients on individual medication plans. Patients are treated according to guidelines that possibly improve depressive symptoms, such as through 
D4 receptor agonists that may impair cognition, as known to occur with dopamine agonists in old age. Due to the moderate sample size, the heterogeneous medication, which was also adjusted several times during the course of the disease, clear effects of PD medication on depressive symptoms and cognition could not be shown. Moreover, information on comorbid psychiatric diagnoses and psychological treatment was only partially available (i.e., for those patients who were treated as inpatients for a specific period of time). Thus, it was not possible to distinguish effects of medical or psychological intervention on depression (and cognition) from effects of aging, social support, cognitive training, etc. Second, the conducted analyses were not preregistered, so this is exploratory rather than confirmatory research (Wagenmakers et al., 2012). Combined with the - for complex latent variable modeling — still modest sample size and the researcher's degrees of freedom in processing the raw data (Simmons et al., 2011), we recommend replicating the results with another sample or conducting a specification curve (e.g., studying the effect with all reasonable specifications; Simonsohn et al., 2019). Third, in the present manuscript, we considered cognitive decline at a highly aggregated level—at the level of general cognitive ability. In principle, a more fine-grained picture would be desirable, even though the evidence for different, domain-specific impairments is sparse and inconsistent (e.g., Aarsland et al., 2017, 2021; Hoogland et al., 2018; Muslimović et al., 2005). Although our understanding of the underlying neurological mechanisms of PD has improved in the last decades (for an overview see Aarsland et al., 2021), the etiology of cognitive impairment in patients with PD is multifactorial and complex, and we still know little about the factors that contribute to or prevent domain-specific impairment. The large heterogeneity of results across studies on cognitive impairments emphasizes the need for large, prospective longitudinal studies with a comprehensive cognitive test battery. Finally, the stability and mutability of cognition and 
affect are different: While changes in cognitive functioning are incremental and in the case of PD tend to signify irreversible losses, depressive symptoms are more volatile and short-term in nature. The biennial follow-ups of our study do not correspond to the time frame (of most subtypes) of depressive disorders, because the average episode duration of a treated unipolar depressive disorder was reported to be 16 weeks (Kessler et al., 2003). By implementing a smartphone-based ecological momentary assessment a finer granularity of analysis would be possible (Yim et al., 2020). Modeling approaches that allow for a separation of between-person and within-person effects (such as the presented RI-CLPM) would be ideally suited to handle such intensive, longitudinal data (e.g., Dynamic Structural Equation Modeling, Asparouhov et al., 2018). It would even be possible to gauge the effect of critical life events such as hospitalization, loss of social support, or the effect of pharmacological treatment or psychotherapy. This would, however, require large sample sizes to take into account the influence of the heterogeneous conditions and the highly individual development trajectories and to avoid capitalizing on chance.

In conclusion, well-conducted observational, longitudinal cohort studies with a broad neuropsychological assessment and carefully selected study participants (both patients and controls that are matched with regard to relevant background variables) are necessary to study the dynamic interplay between non-motor symptoms that besides motor symptoms severely affect the quality of life of patients with PD. Our study results show that, temporally, cognitive decline occurs first and depressive symptomatology increases thereafter. However, this temporal order does not necessarily imply causality (Rohrer \& Murayama, 2021). 


\section{References}

Aarsland, D., Batzu, L., Halliday, G. M., Geurtsen, G. J., Ballard, C., Ray Chaudhuri, K., \& Weintraub, D. (2021). Parkinson disease-associated cognitive impairment. Nature Reviews Disease Primers, 7(1), Article 47. https://doi.org/10.1038/s41572-021-00280-3

Aarsland, D., Bronnick, K., Williams-Gray, C., Weintraub, D., Marder, K., Kulisevsky, J., Burn, D., Barone, P., Pagonabarraga, J., Allcock, L., Santangelo, G., Foltynie, T., Janvin, C., Larsen, J. P., Barker, R. A., \& Emre, M. (2010). Mild cognitive impairment in Parkinson disease: A multicenter pooled analysis. Neurology, 75(12), 1062-1069. https://doi.org/10.1212/WNL.0b013e3181f39d0e

Aarsland, D., Creese, B., Politis, M., Chaudhuri, K. R., ffytche, D. H., Weintraub, D., \& Ballard, C. (2017). Cognitive decline in Parkinson disease. Nature Reviews Neurology, 13(4), 217-231. https://doi.org/10.1038/nrneurol.2017.27

Aarsland, D., Påhlhagen, S., Ballard, C. G., Ehrt, U., \& Svenningsson, P. (2012). Depression in Parkinson disease_epidemiology, mechanisms and management. Nature Reviews Neurology, 8(1), 35-47. https://doi.org/10.1038/nrneurol.2011.189

Aschenbrenner, S., Tucha, O., \& Lange, K. W. (2001). RWT: Regensburger WortflüssigkeitsTest [RWT: Regensburger Verbal Fluency Test]. Hogrefe.

Asparouhov, T., Hamaker, E. L., \& Muthén, B. (2018). Dynamic structural equation models. Structural Equation Modeling: A Multidisciplinary Journal, 25(3), 359-388. https://doi.org/10.1080/10705511.2017.1406803

Barone, P. (2011). Treatment of depressive symptoms in Parkinson's disease. European Journal of Neurology, 18(1), 11-15. https://doi.org/10.1111/j.1468-1331.2010.03325.x 
Bäumler, G. (1985). Farbe-Wort-Interferenztest (FWIT) nach J. R. Stroop [Color Word Interference Test according to J. R. Stroop]. Hogrefe.

Biundo, R., Weis, L., \& Antonini, A. (2016). Cognitive decline in Parkinson's disease: The complex picture. Npj Parkinson's Disease, 2(1), Article 16018. https://doi.org/10.1038/npjparkd.2016.18

Broeders, M., de Bie, R. M. A., Velseboer, D. C., Speelman, J. D., Muslimović, D., \& Schmand, B. (2013). Evolution of mild cognitive impairment in Parkinson disease. Neurology, 81(4), 346-352. https://doi.org/10.1212/WNL.0b013e31829c5c86

Brosseau-Liard, P. E., \& Savalei, V. (2014). Adjusting incremental fit indices for nonnormality. Multivariate Behavioral Research, 49(5), 460-470.

\section{https://doi.org/10.1080/00273171.2014.933697}

Brosseau-Liard, P. E., Savalei, V., \& Li, L. (2012). An investigation of the sample performance of two nonnormality corrections for RMSEA. Multivariate Behavioral Research, 47(6), 904-930. https://doi.org/10.1080/00273171.2012.715252

Chlond, M., Bergmann, F., Güthlin, C., Schnoor, H., Larisch, A., \& Eggert, K. (2016). Patient education for patients with Parkinson's disease: A randomised controlled trial. Basal Ganglia, 6(1), 25-30. https://doi.org/10.1016/j.baga.2015.11.004

Choi, C., Sohn, Y. H., Lee, J. H., \& Kim, J. S. (2000). The effect of long-term levodopa therapy on depression level in de novo patients with Parkinson's disease. Journal of the Neurological Sciences, 172(1), 12-16. https://doi.org/10.1016/S0022-510X(99)00198-7

Deutsche Gesellschaft für Neurologie (DGN). (2021, 25. November). S3-Leitlinie Idiopathisches Parkinson-Syndrom - Langversion [S3 Guidelines Idiopathic Parkinson's Disease - Long 
Version]. https://www.awmf.org/uploads/tx_szleitlinien/030-

0101_S3_Parkinson_Syndrome_Idiopathisch_2016-06-abgelaufen.pdf

Dogan, B., Akyol, A., Memis, C. O., Sair, A., Akyildiz, U., \& Sevincok, L. (2019). The relationship between temperament and depression in Parkinson's disease patients under dopaminergic treatment. Psychogeriatrics, 19(1), 73-79.

\section{https://doi.org/10.1111/psyg.12366}

Dotson, V. M., Beydoun, M. A., \& Zonderman, A. B. (2010). Recurrent depressive symptoms and the incidence of dementia and mild cognitive impairment. Neurology, 75(1), 27-34. https://doi.org/10.1212/WNL.0b013e3181e62124

Enders, C. K. (2010). Applied missing data analysis. The Guilford Press.

Erro, R., Picillo, M., Vitale, C., Amboni, M., Moccia, M., Santangelo, G., Pellecchia, M. T., \& Barone, P. (2016). The non-motor side of the honeymoon period of Parkinson's disease and its relationship with quality of life: A 4-year longitudinal study. European Journal of Neurology, 23(11), 1673-1679. https://doi.org/10.1111/ene.13106

Ferreira, D., Przybelski, S. A., Lesnick, T. G., Lemstra, A. W., Londos, E., Blanc, F., Nedelska, Z., Schwarz, C. G., Graff-Radford, J., Senjem, M. L., Fields, J. A., Knopman, D. S., Savica, R., Ferman, T. J., Graff-Radford, N. R., Lowe, V. J., Jack, C. R., Petersen, R. C., Mollenhauer, B., ... Kantarci, K. (2020). $\beta$-Amyloid and tau biomarkers and clinical phenotype in dementia with Lewy bodies. Neurology, 95(24), e3257-e3268. https://doi.org/10.1212/WNL.0000000000010943

Gallagher, D. A., Lees, A. J., \& Schrag, A. (2010). What are the most important nonmotor symptoms in patients with Parkinson's disease and are we missing them? Movement Disorders, 25(15), 2493-2500. https://doi.org/10.1002/mds.23394 
Gauggel, S., \& Birkner, B. (1999). Validität und Reliabilität einer deutschen Version der Geriatrischen Depressionsskala. GDS [Validity and reliability of a German version of the Geriatric Depression Scale. GDS]. Zeitschrift Für Klinische Psychologie, 28(1), 18-27. https://doi.org/10.1026/0084-5345.28.1.18

Gilman, S., Low, P., Quinn, N., Albanese, A., Ben-Shlomo, Y., Fowler, C., Kaufmann, H., Klockgether, T., Lang, A., Lantos, P., Litvan, I., Mathias, C., Oliver, E., Robertson, D., Schatz, I., \& Wenning, G. (1998). Consensus statement on the diagnosis of multiple system atrophy. Clinical autonomic research, 8(6), 359-362.

\section{https://doi.org/10.1007/BF02309628}

Goldman, J. G., \& Postuma, R. (2014). Premotor and nonmotor features of Parkinson's disease. Current Opinion in Neurology, 27(4), 434-441. https://doi.org/10.1097/WCO.0000000000000112

Goodarzi, Z., Mrklas, K. J., Roberts, D. J., Jette, N., Pringsheim, T., \& Holroyd-Leduc, J. (2016). Detecting depression in Parkinson disease: A systematic review and meta-analysis. Neurology, 87(4), 426-437. https://doi.org/10.1212/WNL.0000000000002898

Graham, J. W. (2003). Adding missing-data-relevant variables to FIML-based structural equation models. Structural Equation Modeling: A Multidisciplinary Journal, 10(1), 80-100. https://doi.org/10.1207/S15328007SEM1001_4

Hamaker, E. L. (2012). Why researchers should think "within-person": A paradigmatic rationale. In M. R. Mehl \& T. S. Conner (Eds.), Handbook of research methods for studying daily life (pp. 43-61). The Guilford Press.

Hamaker, E. L., Kuiper, R. M., \& Grasman, R. P. P. P. (2015). A critique of the cross-lagged panel model. Psychological Methods, 20(1), 102-116. https://doi.org/10.1037/a0038889 
Hanganu, A., Bruneau, M.-A., Degroot, C., Bedetti, C., Mejia-Constain, B., Lafontaine, A.-L., Chouinard, S., \& Monchi, O. (2017). Depressive symptoms in Parkinson's disease correlate with cortical atrophy over time. Brain and Cognition, 111, 127-133.

\section{https://doi.org/10.1016/j.bandc.2016.11.001}

Härting, C., Markowitsch, H. J., Neufeld, U., Calabrese, P., Deisinger, K., \& Kessler, J. (2000). Wechsler Gedächtnis Test - Revidierte Fassung. WMS-R [The revised version of the Wechsler Memory Scale]. Huber.

Hautzinger, M., Bailer, M., Worall, H., \& Kaller, F. (1995). Beck-Depressions-Inventar. BDI. [Beck’s Depression Inventory]. Huber.

Helmstaedter, C., Lendt, M., \& Lux, S. (2001). Verbaler Lern- und Merkfähigkeitstest. VLMT. [Verbal Learning and Memory Test]. Beltz.

Hindle, J. V., Martyr, A., \& Clare, L. (2014). Cognitive reserve in Parkinson's disease: A systematic review and meta-analysis. Parkinsonism \& Related Disorders, 20(1), 1-7.

\section{https://doi.org/10.1016/j.parkreldis.2013.08.010}

Hoogland, J., van Wanrooij, L. L., Boel, J. A., Goldman, J. G., Stebbins, G. T., DalrympleAlford, J. C., Marras, C., Adler, C. H., Junque, C., Pedersen, K. F., Mollenhauer, B., Zabetian, C. P., Eslinger, P. J., Lewis, S. J. G., Wu, R.-M., Klein, M., Rodriguez-Oroz, M. C., Cammisuli, D. M., Barone, P., ... on behalf of the IPMDS Study Group "Validation of Mild Cognitive Impairment in Parkinson Disease." (2018). Detecting mild cognitive deficits in Parkinson's disease: Comparison of neuropsychological tests. Movement Disorders, 33(11), 1750-1759. https://doi.org/10.1002/mds.110 
Hu, L., \& Bentler, P. M. (1999). Cutoff criteria for fit indexes in covariance structure analysis: Conventional criteria versus new alternatives. Structural Equation Modeling: A Multidisciplinary Journal, 6(1), 1-55. https://doi.org/ 10.1080/10705519909540118

Ishihara, L., \& Brayne, C. (2006). A systematic review of depression and mental illness preceding Parkinson's disease. Acta Neurologica Scandinavica, 113(4), 211-220.

\section{https://doi.org/10.1111/j.1600-0404.2006.00579.x}

Jaunarajs, K. L. E., Angoa-Perez, M., Kuhn, D. M., \& Bishop, C. (2011). Potential mechanisms underlying anxiety and depression in Parkinson's disease: Consequences of L-DOPA treatment. Neuroscience and Biobehavioral Reviews, 35(3), 556-564.

\section{https://doi.org/10.1016/j.neubiorev.2010.06.007}

Jones, J. D., Burroughs, M., Apodaca, M., \& Bunch, J. (2020). Greater intraindividual variability in neuropsychological performance predicts cognitive impairment in de novo Parkinson's disease. Neuropsychology, 34(1), 24-30. https://doi.org/10.1037/neu0000577

Jones, J. D., Kurniadi, N. E., Kuhn, T. P., Szymkowicz, S. M., Bunch, J., \& Rahmani, E. (2019). Depressive symptoms precede cognitive impairment in de novo Parkinson's disease patients: Analysis of the PPMI cohort. Neuropsychology, 33(8), 1111-1120. https://doi.org/10.1037/neu0000583

Jones, J. D., Marsiske, M., Okun, M. S., \& Bowers, D. (2015). Latent growth-curve analysis reveals that worsening Parkinson's disease quality of life is driven by depression. Neuropsychology, 29(4), 603-609. https://doi.org/10.1037/neu0000158

Kehagia, A. A., Barker, R. A., \& Robbins, T. W. (2013). Cognitive impairment in Parkinson's disease: The dual syndrome hypothesis. Neurodegenerative Diseases, 11(2), 79-92. https://doi.org/10.1159/000341998 
Kessler, R. C., Berglund, P., Demler, O., Jin, R., Koretz, D., Merikangas, K. R., Rush, A. J., Walters, E. E., \& Wang, P. S. (2003). The epidemiology of major depressive disorder: Results from the National Comorbidity Survey Replication (NCS-R). JAMA, 289(23), 3095-3105. https://doi.org/10.1001/jama.289.23.3095

Ketharanathan, T., Hanwella, R., Weerasundera, R., \& de Silva, V. A. (2014). Major depressive disorder in Parkinson's disease: A cross-sectional study from Sri Lanka. BMC Psychiatry, 14(1), Article 278. https://doi.org/10.1186/s12888-014-0278-8

Kotov, R., Krueger, R. F., Watson, D., Cicero, D. C., Conway, C. C., DeYoung, C. G., Eaton, N. R., Forbes, M. K., Hallquist, M. N., Latzman, R. D., Mullins-Sweatt, S. N., Ruggero, C. J., Simms, L. J., Waldman, I. D., Waszczuk, M. A., \& Wright, A. G. C. (2021). The Hierarchical Taxonomy of Psychopathology (HiTOP): A quantitative nosology based on consensus of evidence. Annual Review of Clinical Psychology, 17(1), 83-108.

\section{https://doi.org/10.1146/annurev-clinpsy-081219-093304}

Leentjens, A. F. G. (2011). The role of dopamine agonists in the treatment of depression in patients with Parkinson's disease. Drugs, 71(3), 273-286.

\section{https://doi.org/10.2165/11585380-000000000-00000}

Lemke, M. R. (2008). Depressive symptoms in Parkinson's disease. European Journal of Neurology, 15(1), 21-25. https://doi.org/10.1111/j.1468-1331.2008.02058.x

Liao, X., Wu, N., Liu, D., Shuai, B., Li, S., \& Li, K. (2020). Levodopa/carbidopa/entacapone for the treatment of early Parkinson's disease: A meta-analysis. Neurological Sciences, 41, 2045-2054. https://doi.org/10.1007/s10072-020-04303-x

Litvan, I., Agid, Y., Calne, D., Campbell, G., Dubois, B., Duvoisin, R. C., Goetz, C. G., Golbe, L. I., Grafman, J., Growdon, J. H., Hallett, M., Jankovic, J., Quinn, N. P., Tolosa, E., \& 
Zee, D. S. (1996). Clinical research criteria for the diagnosis of progressive supranuclear palsy (Steele-Richardson-Olszewski syndrome): Report of the NINDS-SPSP International Workshop. Neurology, 47(1), 1-9. https://doi.org/10.1212/wn1.47.1.1

Litvan, I., Goldman, J. G., Tröster, A. I., Schmand, B. A., Weintraub, D., Petersen, R. C., Mollenhauer, B., Adler, C. H., Marder, K., Williams-Gray, C. H., Aarsland, D., Kulisevsky, J., Rodriguez-Oroz, M. C., Burn, D. J., Barker, R. A., \& Emre, M. (2012). Diagnostic criteria for mild cognitive impairment in Parkinson's disease: Movement Disorder Society Task Force guidelines: PD-MCI Diagnostic Criteria. Movement Disorders, 27(3), 349-356. https://doi.org/10.1002/mds.24893

Mollenhauer, B., Trautmann, E., Sixel-Döring, F., Wicke, T., Ebentheuer, J., Schaumburg, M., Lang, E., Focke, N. K., Kumar, K. R., Lohmann, K., Klein, C., Schlossmacher, M. G., Kohnen, R., Friede, T., \& Trenkwalder, C. (2013). Nonmotor and diagnostic findings in subjects with de novo Parkinson disease of the DeNoPa cohort. Neurology, 81(14), 12261234. https://doi.org/10.1212/WNL.0b013e3182a6cbd5

Mollenhauer, B., Zimmermann, J., Sixel-Döring, F., Focke, N. K., Wicke, T., Ebentheuer, J., Schaumburg, M., Lang, E., Trautmann, E., Zetterberg, H., Taylor, P., Friede, T., \& Trenkwalder, C. (2016). Monitoring of 30 marker candidates in early Parkinson disease as progression markers. Neurology, 87(2), 168-177.

\section{https://doi.org/10.1212/WNL.0000000000002651}

Monastero, R., Cicero, C. E., Baschi, R., Davì, M., Luca, A., Restivo, V., Zangara, C., Fierro, B., Zappia, M., \& Nicoletti, A. (2018). Mild cognitive impairment in Parkinson's disease: The Parkinson's disease cognitive study (PACOS). Journal of Neurology, 265(5), 1050_ 1058. https://doi.org/10.1007/s00415-018-8800-4 
Mulder, J. D., \& Hamaker, E. L. (2020). Three extensions of the random intercept cross-lagged panel model. Structural Equation Modeling: A Multidisciplinary Journal, 28(4). 638648. https://doi.org/10.1080/10705511.2020.1784738

Mund, M., \& Nestler, S. (2019). Beyond the cross-lagged panel model: Next-generation statistical tools for analyzing interdependencies across the life course. Advances in Life Course Research, 41, Article 100249. https://doi.org/10.1016/j.alcr.2018.10.002

Muslimović, D., Post, B., Speelman, J. D., \& Schmand, B. (2005). Cognitive profile of patients with newly diagnosed Parkinson disease. Neurology, 65(8), 1239-1245.

\section{https://doi.org/10.1212/01.wnl.0000180516.69442.95}

Muslimović, D., Schmand, B., Speelman, J. D., \& de Haan, R. J. (2007). Course of cognitive decline in Parkinson's disease: A meta-analysis. Journal of the International Neuropsychological Society, 13(6), 920-932.

\section{https://doi.org/10.1017/S1355617707071160}

Nasreddine, Z. S., Phillips, N. A., Bédirian, V., Charbonneau, S., Whitehead, V., Collin, I., Cummings, J. L., \& Chertkow, H. (2005). The Montreal Cognitive Assessment, MoCA: A brief screening tool for mild cognitive impairment. Journal of the American Geriatrics Society, 53(4), 695-699. https://doi.org/10.1111/j.1532-5415.2005.53221.x

Pankratz, N., Marder, K. S., Halter, C. A., Rudolph, A., Shults, C. W., Nichols, W. C., \& Foroud, T. (2008). Clinical correlates of depressive symptoms in familial Parkinson's disease. Movement Disorders, 23(15), 2216-2223. https://doi.org/10.1002/mds.22285

Pedersen, K. F., Larsen, J. P., Tysnes, O.-B., \& Alves, G. (2017). Natural course of mild cognitive impairment in Parkinson disease: A 5-year population-based study. Neurology, 88(8), 767-774. https://doi.org/10.1212/WNL.0000000000003634 
Perez-Lloret, S., \& Barrantes, F. J. (2016). Deficits in cholinergic neurotransmission and their clinical correlates in Parkinson's disease. Npj Parkinson's Disease, 2(1), Article 16001. https://doi.org/10.1038/npjparkd.2016.1

Petersen, R. C., Roberts, R. O., Knopman, D. S., Boeve, B. F., Geda, Y. E., Ivnik, R. J., Smith, G. E., \& Jack Jr, C. R. (2009). Mild cognitive impairment: Ten years later. Archives of Neurology, 66(12), 1447-1455. https://doi.org/10.1001/archneurol.2009.266

Petkus, A. J., Filoteo, J. V., Schiehser, D. M., Gomez, M. E., \& Petzinger, G. (2019). Worse cognitive performance predicts increased anxiety and depressive symptoms in patients with Parkinson's disease: A bidirectional analysis. Neuropsychology, 33(1), 35-46. https://doi.org/10.1037/neu0000498

Pirogovsky-Turk, E., Moore, R. C., Filoteo, J. V., Litvan, I., Song, D. D., Lessig, S. L., \& Schiehser, D. M. (2017). Neuropsychiatric predictors of cognitive decline in Parkinson disease: A longitudinal study. The American Journal of Geriatric Psychiatry, 25(3), 279289. https://doi.org/10.1016/j.jagp.2016.10.004

Pfeiffer, H. C. V., Løkkegaard, A., Zoetmulder, M., Friberg, L., \& Werdelin, L. (2014). Cognitive impairment in early-stage non-demented Parkinson's disease patients. Acta Neurologica Scandinavica, 129(5), 307-318. https://doi.org/10.1111/ane.12189

Pontone, G. M., Bakker, C. C., Chen, S., Mari, Z., Marsh, L., Rabins, P. V., Williams, J. R., \& Bassett, S. S. (2015). The longitudinal impact of depression on disability in Parkinson disease. International Journal of Geriatric Psychiatry, 31(5), 458-465. https://doi.org/10.1002/gps.4350 
Pringsheim, T., Jette, N., Frolkis, A., \& Steeves, T.D. (2014). The prevalence of Parkinson's disease: A systematic review and meta-analysis. Movement Disorders, 29(13), 15831590. https://doi.org/10.1002/mds.25945

R Core Team (2021). R: A language and environment for statistical computing (Version 4.1.0). https://www.R-project.org/

Rascol, O., Payoux, P., Ory, F., Ferreira, J. J., Brefel-Courbon, C., \& Montastruc, J.-L. (2003). Limitations of current Parkinson's disease therapy. Annals of Neurology, 53(S3), S3-S15. https://doi.org/10.1002/ana.10513

Reijnders, J. S., Ehrt, U., Weber, W. E., Aarsland, D., \& Leentjens, A. F. (2008). A systematic review of prevalence studies of depression in Parkinson's disease. Movement Disorders, 23(2), 183-189. https://doi.org/10.1002/mds.21803

Riedel, O., Heuser, I., Klotsche, J., Dodel, R., Wittchen, H.-U., \& GEPAD Study Group. (2010). Occurrence risk and structure of depression in Parkinson disease with and without dementia: Results from the GEPAD study. Journal of Geriatric Psychiatry and Neurology, 23(1), 27-34. https://doi.org/10.1177/0891988709351833

Riedel, O., Klotsche, J., Spottke, A., Deuschl, G., Förstl, H., Henn, F., Heuser, I., Oertel, W., Reichmann, H., Riederer, P., Trenkwalder, C., Dodel, R., \& Wittchen, H.-U. (2010). Frequency of dementia, depression, and other neuropsychiatric symptoms in 1,449 outpatients with Parkinson's disease. Journal of Neurology, 257(7), 1073-1082. https://doi.org/10.1007/s00415-010-5465-Z

Rocca, W. A. (2018). The burden of Parkinson's disease: A worldwide perspective. The Lancet Neurology, 17(11), 928-929. https://doi.org/10.1016/S1474-4422(18)30355-7 
Roheger, M., Kalbe, E., \& Liepelt-Scarfone, I. (2018). Progression of cognitive decline in Parkinson's disease. Journal of Parkinson's Disease, 8(2), 183-193. https://doi.org/10.3233/JPD-181306

Rohrer, J. M., \& Murayama, K. (2021). These are not the effects you are looking for: Causality and the within-/between-person distinction in longitudinal data analysis. PsyArXiv. https://doi.org/10.31234/osf.io/tg4vj

Rosseel, Y. (2012). lavaan: An R package for structural equation modeling. Journal of Statistical Software, 48(2), 1-36. http://www.jstatsoft.org/v48/i02/

Ravina, B., Camicioli, R., Como, P. G., Marsh, L., Jankovic, J., Weintraub, D., \& Elm, J. (2007). The impact of depressive symptoms in early Parkinson disease. Neurology, 69(4), 342347. https://doi.org/10.1212/01.wnl.0000268695.63392.10

Ryan, M., Eatmon, C. V., \& Slevin, J. T. (2019). Drug treatment strategies for depression in Parkinson disease. Expert Opinion on Pharmacotherapy, 20(11), 1351-1363. $\underline{\text { https://doi.org/10.1080/14656566.2019.1612877 }}$

Sanyal, J., Banerjee, T. K., \& Rao, V. R. (2014). Dementia and cognitive impairment in patients with Parkinson's disease from India: A 7-year prospective study. American Journal of Alzheimer's Disease \& Other Dementias, 29(7), 630-636. https://doi.org/10.1177/1533317514531442

Schaeffer, E., \& Berg, D. (2017). Dopaminergic therapies for non-motor symptoms in Parkinson's disease. CNS Drugs, 31(7), 551-570. https://doi.org/10.1007/s40263-017$\underline{0450-\mathrm{Z}}$

Schafer, J. L., \& Graham, J. W. (2002). Missing data: Our view of the state of the art. Psychological Methods, 7(2), 147-177. https://doi.org/10.1037/1082-989X.7.2.147 
Schmidtke, A., Fleckenstein, P., Moises, W., \& Beckmann, H. (1988). Untersuchungen zur Reliabilität und Validität einer deutschen Version der Montgomery-Asberg Depression Rating Scale [Studies of the reliability and validity of the German version of the Montgomery-Asberg Depression Rating Scale]. Schweizer Archiv für Neurologie und Psychiatrie, 139(2), 51-65.

Schrag, A., Jahanshahi, M., \& Quinn, N. (2000). What contributes to quality of life in patients with Parkinson's disease? Journal of Neurology, Neurosurgery \& Psychiatry, 69(3), 308312. https://doi.org/10.1136/jnnp.69.3.308

Simmons, J. P., Nelson, L. D., \& Simonsohn, U. (2011). False-positive psychology: Undisclosed flexibility in data collection and analysis allows presenting anything as significant. Psychological Science, 22(11), 1359-1366. https://doi.org/10.1177/0956797611417632

Simonsohn, U., Simmons, J. P., \& Nelson, L. D. (2019). Specification curve: Descriptive and inferential statistics on all reasonable specifications. SSRN Electronic Journal. https://doi.org/10.2139/ssrn.2694998

Tombaugh T. N. (2004). Trail Making Test A and B: Normative data stratified by age and education. Archives of Clinical Neuropsychology, 19(2), 203-214. https://doi.org/10.1016/S0887-6177(03)00039-8

Tomlinson, C. L., Stowe, R., Patel, S., Rick, C., Gray, R., \& Clarke, C. E. (2010). Systematic review of levodopa dose equivalency reporting in Parkinson's disease: Systematic Review of LED Reporting in PD. Movement Disorders, 25(15), 2649-2653. $\underline{\text { https://doi.org/10.1002/mds.23429 }}$

von Aster, M., Neubauer, A., \& Horn, R. (Eds.). (2006). Wechsler Intelligenztest für Erwachsene. WIE [Wechsler Adult Intelligence Scale. WAIS-III]. Pearson Assessment. 
von Glischinski, M., von Brachel, R., Thiele, C., \& Hirschfeld, G. (2021). Not sad enough for a depression trial? A systematic review of depression measures and cut points in clinical trial registrations. Journal of affective disorders, 292, 36-44. https://doi.org/10.1016/j.jad.2021.05.041

Wagenmakers, E.-J., Wetzels, R., Borsboom, D., van der Maas, H. L. J., \& Kievit, R. A. (2012). An agenda for purely confirmatory research. Perspectives on Psychological Science, 7(6), 632-638. https://doi.org/10.1177/1745691612463078

Wahl, I., Löwe, B., Bjorner, J. B., Fischer, F., Langs, G., Voderholzer, U., Aita, S. A., Bergemann, N., Brähler, E., \& Rose, M. (2014). Standardization of depression measurement: A common metric was developed for 11 self-report depression measures. Journal of Clinical Epidemiology, 67(1), 73-86.

\section{https://doi.org/10.1016/j.jclinepi.2013.04.019}

Wang, X., Becker, K., Levine, N., Zhang, M., Lieberman, A. P., Moore, D. J., \& Ma, J. (2019). Pathogenic alpha-synuclein aggregates preferentially bind to mitochondria and affect cellular respiration. Acta Neuropathologica Communications, 7, Article 41. https://doi.org/10.1186/s40478-019-0696-4

Weintraub, D., \& Mamikonyan, E. (2019). The neuropsychiatry of Parkinson disease: A perfect storm. The American Journal of Geriatric Psychiatry, 27(9), 998-1018. https://doi.org/10.1016/j.jagp.2019.03.002

Weintraub, D., Oehlberg, K. A., Katz, I. R., \& Stern, M. B. (2006). Test characteristics of the 15item Geriatric Depression Scale and Hamilton Depression Rating Scale in Parkinson disease. The American Journal of Geriatric Psychiatry, 14(2), 169-175. https://doi.org/10.1097/01.JGP.0000192488.66049.4b 
Wen, M. -C., Chan, L. L., Tan, L. C. S., \& Tan, E. K. (2016). Depression, anxiety, and apathy in Parkinson's disease: Insights from neuroimaging studies. European Journal of Neurology, 23(6), 1001-1019. https://doi.org/10.1111/ene.13002

Yarnall, A. J., Breen, D. P., Duncan, G. W., Khoo, T. K., Coleman, S. Y., Firbank, M. J., Nombela, C., Winder-Rhodes, S., Evans, J. R., Rowe, J. B., Mollenhauer, B., Kruse, N., Hudson, G., Chinnery, P. F., O’Brien, J. T., Robbins, T. W., Wesnes, K., Brooks, D. J., Barker, R. A., \& Burn, D. J. (2014). Characterizing mild cognitive impairment in incident Parkinson disease: The ICICLE-PD study. Neurology, 82(4), 308-316.

\section{https://doi.org/10.1212/WNL.0000000000000066}

Yim, S. J., Lui, L. M. W., Lee, Y., Rosenblat, J. D., Ragguett, R.-M., Park, C., Subramaniapillai, M., Cao, B., Zhou, A., Rong, C., Lin, K., Ho, R. C., Coles, A. S., Majeed, A., Wong, E. R., Phan, L., Nasri, F., \& McIntyre, R. S. (2020). The utility of smartphone-based, ecological momentary assessment for depressive symptoms. Journal of Affective Disorders, 274, 602-609. https://doi.org/10.1016/j.jad.2020.05.116

Zhang, H., Gu, Z., An, J., Wang, C., \& Chan, P. (2014). Non-motor symptoms in treated and untreated Chinese patients with early Parkinson's disease. The Tohoku Journal of Experimental Medicine, 232(2), 129-136. https://doi.org/10.1620/tjem.232.129 


\section{Table 1}

Demographic Data of Patients With PD and Healthy Controls at Baseline

\begin{tabular}{|c|c|c|c|}
\hline & $\begin{array}{r}\text { Patients with PD } \\
(n=123)\end{array}$ & $\begin{array}{r}\text { Healthy controls } \\
\qquad(n=107)\end{array}$ & $p$ \\
\hline Mean age $(S D)$ [years] & $63.7(9.5)$ & $64.6(6.8)$ & .42 \\
\hline Male/Female (\%) & $79 / 44(64 / 36 \%)$ & $64 / 43(60 / 40 \%)$ & .49 \\
\hline Education $(\%)$ & & & .81 \\
\hline vocational-track Hauptschule/Volksschule & $66(54 \%)$ & $57(53 \%)$ & \\
\hline intermediate-track Realschule & $35(28 \%)$ & $30(28 \%)$ & \\
\hline academic-track Gymnasium & $6(5 \%)$ & $3(3 \%)$ & \\
\hline university & $16(13 \%)$ & $17(16 \%)$ & \\
\hline
\end{tabular}

Note. $P$-values are based on the Welch's $t$-test for the variables age and sex, and the $\chi^{2}$-test of homogeneity for the variable education. 


\section{Table 2}

Overview of Cognitive Ability Tests

Measure

Digit Span

Montreal Cognitive Assessment

Regensburger Word Fluency Test

Similarities

Stroop $^{\text {a }}$

Trail Making Test $\mathrm{t}^{\mathrm{a}}$

Verbal Learning and Memory Test

\section{Task/ Indicator label}

The subtest Digit Span of the Wechsler Memory Scale - Revised assesses the longest list of items a person can repeat back in correct (or reverse) order.

WMS: total digit span (digit span forward + backward) Screening instrument to detect mild cognitive impairment, including different cognitive domains: Attention, executive functions, memory, language, visuospatial skills, abstraction, and orientation.

MoCa: Sum score

In 2 minutes participants have to name as many words as possible that correspond to the following instructions:

RWTa: lexical verbal fluency (words starting with P)

RWTb: semantic verbal fluency (animals)

RWTc: lexical verbal fluency change (words alternating starting with $\mathrm{G} / \mathrm{R}$ )

RWTd: semantic verbal fluency change (alternating sports, fruits)

In the subtest Similarities of the German version of the Wechsler Adult Intelligence Scale (WAIS-III) participants have to find an umbrella term or common characteristic of 2 items. The test measures both abstraction and language abilities.

WIE: Sum score

Names of colors either match the color or are presented in a different color than the color named (inference).

STROOP: Median response time of inferences

Test combines visual search, speed of processing, mental flexibility, and executive functions.

TMTa: Participants have to draw lines sequentially connecting 25 encircled numbers on a sheet of paper.

TMTb: Task requirements are similar with the exception that the person must alternate between numbers and letters (1, A, 2, B, 3, C, etc.).

A test for list learning ( 5 times presentation of a 15 items target list) followed by distraction (single presentation of another 15 items inference list), recall after distraction and half-hour delay, and a recognition pass.

VLMTa: Immediate recall

VLMTb: Delayed recall after distraction

VLMTc: Adjusted recall or recognition (indicate whether item on the target list)

Note. ${ }^{\text {a }}$ Response times were inverse $\log$-transformed $(=1 / \log (\mathrm{RT}))$ 


\section{Table 3}

Descriptive Statistics for all Subtests of Cognitive Abilities and Depressive Symptoms

Patients with PD

Digit Span (Wechsler Memory Scale - Revised)

Montreal Cognitive Assessment

Regensburger Word Fluency Test (letter)

Regensburger Word Fluency Test (semantic)

Regensburger Word Fluency Test (letter change)

Regensburger Word Fluency Test (semantic change)

Similarities (Wechsler Adult Intelligence Scale)

Stroop Test ${ }^{\mathrm{a}}$

Trail Making Test (numbers) ${ }^{\mathrm{a}}$

Trail Making Test (numbers-letters) ${ }^{\mathrm{a}}$

Verbal Learning and Memory Test (immediate recall)

Verbal Learning and Memory Test (delayed recall)

Verbal Learning and Memory Test (adjusted recall)

Beck Depression Inventory

Geriatric Depression Scale

Montgomery-Åsberg Depression Rating Scale

\begin{tabular}{|c|c|c|c|c|c|c|c|c|c|c|c|c|c|c|}
\hline \multicolumn{15}{|c|}{ Patients with PD } \\
\hline \multicolumn{3}{|c|}{ Baseline } & \multicolumn{3}{|c|}{2 years FU } & \multicolumn{3}{|c|}{4 years FU } & \multicolumn{3}{|c|}{6 years FU } & \multicolumn{3}{|c|}{8 years FU } \\
\hline$n$ & $M$ & $S D$ & $n$ & $M$ & $S D$ & $n$ & $M$ & $S D$ & $n$ & $M$ & $S D$ & $n$ & $M$ & $S D$ \\
\hline 122 & 12.8 & 3.3 & 122 & 12.3 & 3.1 & 115 & 12.3 & 3.4 & 98 & 12.8 & 3.4 & 83 & 12.7 & 3.1 \\
\hline 123 & 25.4 & 2.7 & 122 & 24.3 & 3.1 & 116 & 24.7 & 3.7 & 99 & 25.0 & 3.4 & 86 & 24.6 & 3.7 \\
\hline 121 & 12.9 & 5.9 & 121 & 15.6 & 6.3 & 112 & 13.9 & 7.0 & 96 & 16.8 & 6.6 & 81 & 13.9 & 6.1 \\
\hline 121 & 30.5 & 8.5 & 121 & 29.8 & 8.7 & 114 & 30.8 & 9.6 & 96 & 28.5 & 9.5 & 82 & 29.0 & 9.3 \\
\hline 119 & 16.6 & 5.6 & 119 & 17.2 & 6.0 & 112 & 16.2 & 7.0 & 95 & 17.9 & 6.8 & 82 & 17.1 & 7.1 \\
\hline 120 & 18.0 & 4.6 & 121 & 18.0 & 5.7 & 114 & 18.0 & 5.5 & 95 & 18.3 & 5.6 & 81 & 17.2 & 5.4 \\
\hline 122 & 23.1 & 5.3 & 120 & 23.7 & 5.5 & 112 & 23.7 & 5.0 & 98 & 23.5 & 5.1 & 82 & 22.9 & 5.5 \\
\hline 115 & 95.7 & 26.1 & 118 & 93.7 & 29.7 & 107 & 94.2 & 31.2 & 91 & 96.4 & 33.1 & 78 & 95.6 & 32.2 \\
\hline 119 & 48.1 & 25.6 & 119 & 47.3 & 22.7 & 113 & 50.0 & 37.9 & 97 & 48.8 & 29.3 & 83 & 51.6 & 39.9 \\
\hline 118 & 126.1 & 64.3 & 118 & 136.5 & 71.1 & 111 & 142.1 & 80.5 & 94 & 139.6 & 81.5 & 80 & 148.1 & 82.4 \\
\hline 118 & 7.4 & 3.5 & 121 & 7.3 & 3.6 & 114 & 6.5 & 3.6 & 98 & 7.3 & 3.6 & 80 & 8.6 & 3.8 \\
\hline 117 & 7.3 & 3.6 & 121 & 7.2 & 3.5 & 114 & 6.3 & 3.8 & 98 & 7.3 & 3.8 & 80 & 8.7 & 3.9 \\
\hline 118 & 9.1 & 4.7 & 121 & 8.7 & 5.1 & 114 & 6.8 & 5.5 & 98 & 8.5 & 4.8 & 80 & 9.7 & 4.8 \\
\hline 120 & 8.7 & 6.0 & 122 & 7.9 & 5.6 & 112 & 7.6 & 5.7 & 95 & 7.6 & 5.6 & 82 & 8.0 & 6.2 \\
\hline 119 & 3.4 & 2.9 & 122 & 3.0 & 2.7 & 114 & 2.7 & 2.5 & 98 & 2.9 & 2.8 & 85 & 3.2 & 3.0 \\
\hline 116 & 8.3 & 5.6 & 121 & 4.9 & 5.2 & 114 & 3.6 & 4.4 & 98 & 4.3 & 5.6 & 82 & 5.3 & 5.4 \\
\hline
\end{tabular}


Healthy controls

Digit Span (Wechsler Memory Scale - Revised)

Montreal Cognitive Assessment

Regensburger Word Fluency Test (letter)

Regensburger Word Fluency Test (semantic)

Regensburger Word Fluency Test (letter change)

Regensburger Word Fluency Test (semantic change)

Similarities (Wechsler Adult Intelligence Scale)

Stroop Test ${ }^{\mathrm{a}}$

Trail Making Test (numbers) ${ }^{\mathrm{a}}$

Trail Making Test (numbers-letters) ${ }^{\mathrm{a}}$

Verbal Learning and Memory Test (immediate recall)

Verbal Learning and Memory Test (delayed recall)

Verbal Learning and Memory Test (adjusted recall)

\begin{tabular}{|c|c|c|c|c|c|c|c|c|c|c|c|c|c|c|}
\hline \multicolumn{15}{|c|}{ Healthy controls } \\
\hline \multicolumn{3}{|c|}{ Baseline } & \multicolumn{3}{|c|}{2 years FU } & \multicolumn{3}{|c|}{4 years FU } & \multicolumn{3}{|c|}{6 years FU } & \multicolumn{3}{|c|}{8 years FU } \\
\hline$n$ & $M$ & $S D$ & $n$ & $M$ & $S D$ & $n$ & $M$ & $S D$ & $n$ & $M$ & $S D$ & $n$ & $M$ & $S D$ \\
\hline 107 & 13.9 & 3.5 & 105 & 13.5 & 2.9 & 98 & 13.8 & 3.5 & 91 & 13.7 & 3.2 & 82 & 13.6 & 3.2 \\
\hline 107 & 26.0 & 2.3 & 105 & 25.6 & 2.5 & 101 & 26.1 & 2.6 & 94 & 26.6 & 2.4 & 83 & 25.9 & 2.6 \\
\hline 107 & 15.8 & 6.5 & 105 & 19.0 & 6.8 & 99 & 17.3 & 6.1 & 91 & 18.3 & 6.7 & 81 & 16.2 & 6.5 \\
\hline 107 & 34.7 & 7.4 & 105 & 33.8 & 9.1 & 99 & 35.1 & 8.6 & 91 & 34.4 & 9.6 & 82 & 34.6 & 9.3 \\
\hline 106 & 19.2 & 6.0 & 104 & 20.0 & 6.1 & 99 & 20.4 & 6.4 & 91 & 20.2 & 6.3 & 81 & 20.1 & 6.2 \\
\hline 107 & 20.6 & 4.5 & 105 & 20.7 & 5.3 & 98 & 21.3 & 5.1 & 91 & 20.5 & 5.4 & 81 & 20.8 & 5.2 \\
\hline 106 & 25.1 & 5.4 & 105 & 25.6 & 4.6 & 97 & 25.3 & 5.0 & 91 & 25.8 & 4.3 & 81 & 24.9 & 4.9 \\
\hline 104 & 79.2 & 15.7 & 104 & 77.2 & 14.0 & 96 & 75.2 & 13.1 & 89 & 76.9 & 13.4 & 81 & 81.6 & 18.1 \\
\hline 107 & 38.8 & 15.1 & 105 & 34.8 & 12.0 & 98 & 33.6 & 11.9 & 91 & 33.2 & 11.9 & 82 & 34.0 & 12.4 \\
\hline 107 & 101.5 & 50.5 & 105 & 99.4 & 48.0 & 98 & 94.8 & 49.1 & 91 & 95.3 & 43.3 & 82 & 110.3 & 65.6 \\
\hline 105 & 8.7 & 3.5 & 104 & 8.8 & 3.1 & 95 & 7.6 & 3.3 & 90 & 8.3 & 3.3 & 82 & 9.5 & 3.4 \\
\hline 105 & 8.2 & 3.5 & 104 & 8.8 & 3.2 & 96 & 7.4 & 3.5 & 90 & 7.9 & 3.3 & 82 & 9.3 & 3.7 \\
\hline 103 & 9.9 & 4.6 & 104 & 9.9 & 3.9 & 96 & 8.5 & 4.5 & 90 & 9.9 & 4.1 & 82 & 11.1 & 4.1 \\
\hline 107 & 3.3 & 3.8 & 107 & 3.5 & 3.7 & 99 & 3.6 & 4.0 & 92 & 3.8 & 4.0 & 80 & 3.5 & 3.4 \\
\hline 104 & 1.1 & 1.5 & 107 & 1.1 & 1.8 & 101 & 1.2 & 1.7 & 91 & 1.1 & 1.8 & 83 & 1.1 & 1.7 \\
\hline 107 & 3.9 & 4.7 & 104 & 1.9 & 3.7 & 97 & 1.6 & 3.6 & 90 & 2.2 & 4.1 & 82 & 2.4 & 3.4 \\
\hline
\end{tabular}

Beck Depression Inventory

Geriatric Depression Scale

$\begin{array}{llllll}107 & 3.9 & 4.7 & 104 & 1.9 & 3.7\end{array}$

$97 \quad 1.6 \quad 3.6$

$\begin{array}{lll}90 & 2.2 & 4.1 \\ \text { of the healthy controls. }\end{array}$

Note. FU $=$ follow-up. The data were winsorized $\left(M \pm 2.5^{*} S D\right)$, but not yet standardized to the base
${ }^{a}$ Response time data [sec.] and are not yet inverse log-transformed $(=1 / \log (\mathrm{RT}))$ or winsorized. 


\section{Table 4}

Results of the RI-CLPM for the Interplay Between Cognitive Functioning and Depressive Symptoms

\begin{tabular}{|c|c|c|c|c|c|c|}
\hline & \multicolumn{3}{|c|}{ Patients with PD } & \multicolumn{3}{|c|}{ Healthy controls } \\
\hline & $b$ & $S E$ & $p$ & $b$ & $S E$ & $p$ \\
\hline \multicolumn{7}{|c|}{ Autoregressive effects (within persons) } \\
\hline Cognitive abilities & $0.82 *$ & 0.11 & $<.01$ & $0.27 *$ & 0.11 & .02 \\
\hline Depressive symptoms & 0.14 & 0.10 & .17 & $0.28 *$ & 0.12 & .02 \\
\hline $\begin{array}{l}\text { Cross-lagged effects (within } p \\
\text { Cognitive abilities } \rightarrow\end{array}$ & ns) & & & & & \\
\hline $\begin{array}{l}\text { Depressive symptoms } \\
\text { Depressive symptoms } \rightarrow\end{array}$ & $-0.60 *$ & 0.28 & .03 & -0.14 & 0.18 & .43 \\
\hline Cognitive abilities & -0.03 & 0.06 & .66 & 0.02 & 0.04 & .56 \\
\hline
\end{tabular}

Time-point specific associations between cognitive abilities and depressive symptoms (within persons)

$\begin{array}{lrrrrrr}\text { Baseline } & 0.13 & 0.10 & .22 & -0.03 & 0.02 & .18 \\ \text { 2 years follow-up } & -0.11 & 0.06 & .08 & <0.01 & 0.01 & .85 \\ \text { 4 years follow-up } & -0.07 & 0.04 & .06 & -0.07 * & 0.03 & .01 \\ \text { 6 years follow-up } & -0.04 & 0.07 & .59 & -0.04 & 0.02 & .08 \\ \text { 8 years follow-up } & -0.09 & 0.07 & .18 & -0.05 & 0.03 & .08\end{array}$

Random-intercepts association (between persons)

Covariance

$-0.24 * \quad 0.11$ .03 $-0.08 \quad 0.04$ .06

Note. $b=$ Unstandardized parameter estimates; $n(\mathrm{PD})=123 ; n(\mathrm{HC})=107 . p<.05$. 


\section{Figure 1}

Intraindividual Development of Depressive Symptoms and Cognitive Functioning
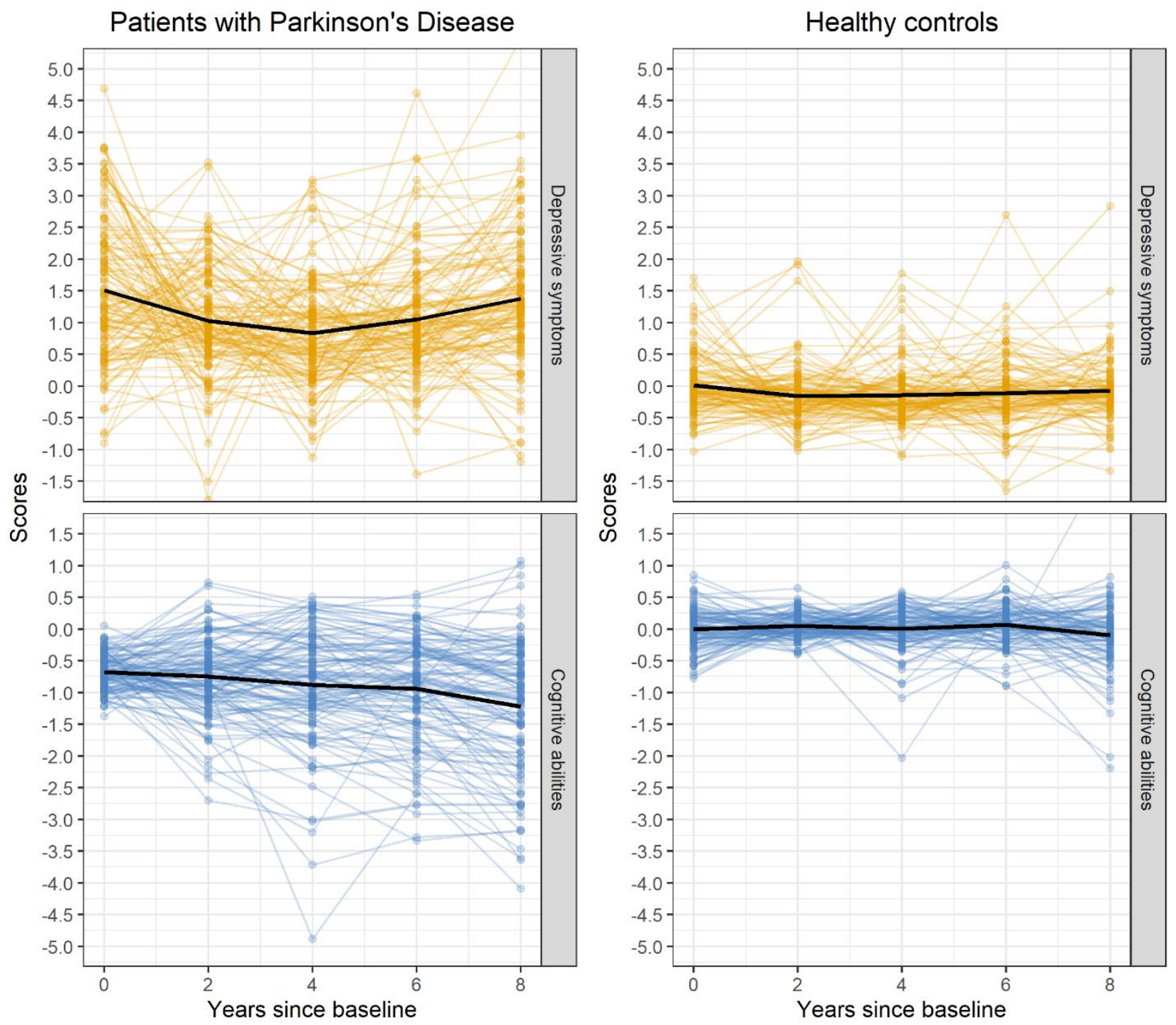

Note. $n(\mathrm{PD})=123 ; n(\mathrm{HC})=107$. Depressive symptoms (upper panels) and cognitive abilities (lower panels) of patients with Parkinson's disease (left panels) and healthy controls (right panels). Values depicted are not observed, but model-implied. 